\title{
Direct and Indirect Costs of Chronic Obstructive Pulmonary Disease in Korea
}

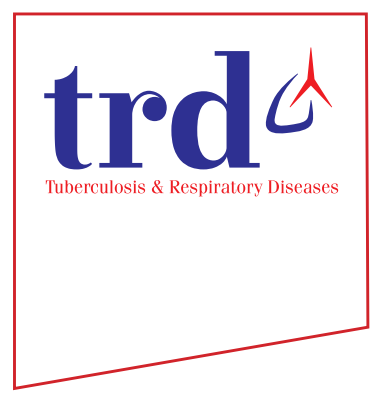

Changhwan Kim, M.D. ${ }^{1, *(\mathbb{D}}$, Younhee Kim, Ph.D. ${ }^{2 *}$, Dong-Wook Yang, Ph.D. ${ }^{3}$, Chin Kook Rhee, M.D. , Sung Kyoung Kim, M.D. ${ }^{5}$, Yong-Il Hwang, M.D. ${ }^{6}$, Yong Bum Park, M.D. ${ }^{7}$, Young Mok Lee, M.D. ${ }^{8}$, Seonglim Jin, M.D. ${ }^{9}$, Jinkyeong Park, M.D. ${ }^{10}$, Cho-Rom Hahm, M.D. ${ }^{11}$, Chang-Han Park, M.D. ${ }^{12}$, So Yeon Park, M.D. ${ }^{13}$, Cheol Kweon Jung, M.D. ${ }^{14}$, Yu-Il Kim, M.D. ${ }^{15}$, Sang Haak Lee, M.D. ${ }^{16}$, Hyoung Kyu Yoon, M.D. ${ }^{17}$, Jin Hwa Lee, M.D. ${ }^{18}$, Seong Yong Lim, M.D. ${ }^{19}$ and Kwang Ha Yoo, M.D., Ph.D. ${ }^{20}$ (iD

*Author affiliations appear at the end of this article.

Background: Understanding the burden of disease is important to establish cost-effective treatment strategies and to allocate healthcare resources appropriately. However, little reliable information is available regarding the overall economic burden imposed by chronic obstructive pulmonary disease (COPD) in Korea.

Methods: This study is a multicenter observational research on the COPD burden in Korea. Total COPD costs were comprised of three categories: direct medical, direct non-medical, and indirect costs. For direct medical costs, institutional investigation was performed at 13 medical facilities mainly based on the claims data. For direct non-medical and indirect costs, site-based surveys were administered to the COPD patients during routine visits. Total costs were estimated using the COPD population defined in the recent report.

Results: The estimated total costs were approximately 1,245 million US dollar (1,408 billion Korean won). Direct medical costs comprised approximately $20 \%$ of the total estimated costs. Of these, formal medical costs held more than 80\%. As direct non-medical costs, nursing costs made up the largest percentage (39\%) of the total estimated costs. Costs for COPD-related loss of productivity formed four fifths of indirect costs, and accounted for up to $33 \%$ of the total costs. Conclusion: This study shows for the first time the direct and indirect costs of COPD in Korea. The total costs were enormous, and the costs of nursing and lost productivity comprised approximately $70 \%$ of total costs. The results provide insight for an effective allocation of healthcare resources and to inform establishment of strategies to reduce national burden of COPD.

Keywords: Pulmonary Disease, Chronic Obstructive; Health Care Costs; Korea

Address for correspondence: Kwang Ha Yoo, M.D., Ph.D.

Division of Pulmonary and Critical Care Medicine, Department of Internal Medicine, Konkuk University School of Medicine, 120 Neungdong-ro,

Gwangjin-gu, Seoul 05029, Korea

Phone: 82-2-2030-7522, Fax: 82-2-2030-7748, E-mail: khyou@kuh.ac.kr

*Changhwan Kim and Younhee Kim contributed equally to this work.

Received: Apr. 3, 2018, Revised: Jun. 25, 2018, Accepted: Jun. 27, 2018, Published online: Sep. 28, 2018

(c) It is identical to the Creative Commons Attribution Non-Commercial License (http://creativecommons.org/licenses/by-nc/4.0/). 


\section{Introduction}

Chronic disease management is one of the healthcare system's greatest challenges. The burden of non-communicable diseases is increasing worldwide, and chronic respiratory diseases play a major role in this growth ${ }^{1}$. Chronic obstructive pulmonary disease (COPD) is the third most frequent cause of death in the world and its global burden is predicted to increase further ${ }^{2}$. According to the nationwide data from Korea National Health and Nutrition Examination Survey (KNHANES), the prevalence of COPD among Korean adults aged over 40 years was as high as $13.4 \%$ in $2015^{3}$. It has been estimated that mortality from COPD will increase by $30 \%$ within 10 years, and COPD ranked seventh among the causes of death in Korea in 2008 (mortality rate, 14.8 per 100,000 population $)^{4}$. Consequentially, the burden on national health services would have been substantially increasing. For instance, the total hospitalization expenses associated with COPD increased from 110 million US dollar (USD) in 2004 to 170 million USD in $2007^{4}$.

A comprehensive understanding of a disease burden is important for identifying cost-effective treatment strategies to minimize their impact and to appropriately allocate healthcare resources. However, little reliable information is available regarding the overall economic burden imposed by COPD at a nationwide level in Korea. A recent report revealed the rapid increase of medical costs in Korean patients with COPD, but the results included only direct reimbursed costs from the database of the Korean Health Insurance Review and Assessment Service (KHIRA) ${ }^{5}$. Besides that, we should also consider direct informal, direct nonmedical, and indirect costs such as use of complementary and alternative medicines, transportation expenses, nursing care costs, and the loss of productivity for a thorough investigation of the total economic burden of COPD. Therefore, the purpose of the present study was to estimate in detail both direct and indirect costs and to inform establishment of efficient strategies to reduce the financial burden of COPD in Korea.

\section{Materials and Methods}

\section{Study design}

This study is a multicenter observational research on the economic burden of COPD in Korea. Total COPD costs were comprised of three categories. These categories and resources used for estimation were presented schematically in Table 1. Direct medical costs include the formal expense on medication and outpatient and inpatient care including emergency visit, and the informal expense on complementary and alternative medicines (CAMS) and on medical equipment. Direct non-medical costs include the expense on transportation and nursing care. Indirect costs include the opportunity costs of COPD-related loss of productivity and premature death.

To estimate direct formal and a part of direct informal (nonreimbursed) medical costs, institutional investigation was performed mainly based on the claims data from KHIRA. The costs were added up according to the type of medical facility and then the average cost per patient was derived. After that, total costs were calculated by multiplying each average cost, percent distribution of facility type, and total COPD population in Korea. We applied the COPD population and percent distribution of facility type defined in the recent reports based on the KHIRA database ${ }^{5,6}$.

To estimate costs for CAMS, medical equipment, nursing, and loss of productivity, site-based surveys were administered to the patients diagnosed with COPD during routine visits. The costs were added up according to the severity of airflow limitation and then the average cost per patient was derived. After that, total costs were calculated by multiplying each average cost, percent distribution of COPD severity, and total COPD population in Korea as mentioned above. We accepted the percent distribution of COPD severity in another recent study of a multicenter cohort in Korea? ${ }^{7}$. The expense for transportation was estimated based on the number of outpatient and inpatient visits and on the per case transportation fee from Korea Health Panel data. The costs of premature death were calculated using the number of COPD-related deaths

Table 1. COPD cost categories and resources used for estimation

\begin{tabular}{|cl|}
\hline \multicolumn{1}{|c|}{ Category } & \multicolumn{1}{c|}{ Data sources } \\
\hline Direct medical & \\
Formal & \multicolumn{1}{c|}{ Institutional investigation } \\
RHIRA
\end{tabular}

COPD: chronic obstructive pulmonary disease; KHIRA: Korean Health Insurance Review and Assessment Service; CAMs: complementary and alternative medicines. 
from national cause of death statistics and the expected future income based on demographic characteristics.

All costs are presented in USD ( 1 USD $=1,131$ Korean won $[\mathrm{KRW}]$, as of the average annual exchange rate for 2015).

\section{Institutional investigation for direct medical cost estimation}

A total of 373 subjects have been recruited for this investigation from 13 medical facilities ( 1 primary, 6 secondary, and 6 tertiary facilities) since October 2013. The patients fulfilling all the following criteria were included: (1) having a physician diagnosis of COPD over 1 year, (2) aged 40 or over, and (3) without malignant diseases. The number of study subjects was assigned according to the COPD severity to each of the facilities ( $10 \%$ for mild, $40 \%$ for moderate, $30 \%$ for severe, and $20 \%$ for very severe COPD). The severity of COPD was categorized by Global Initiative for Chronic Obstructive Lung Disease (GOLD) criteria based on the post-bronchodilator forced expiratory volume in one second $\left(\mathrm{FEV}_{1}\right)$ as a percentage of predicted normal values (\% predicted): mild, stage I, $\mathrm{FEV}_{1} \geq 80 \%$; moderate, stage II, $50 \% \leq \mathrm{FEV}_{1}<80 \%$; severe, stage III, $30 \% \leq \mathrm{FEV}_{1}<50 \%$; and very severe, stage IV, $\mathrm{FEV}_{1}<30 \%$.

One-year expense on outpatient and inpatient care including emergency visit was summed up using the receipts of medical expenses and the claims data of KHIRA for each patient. Formal expense on outpatient medication was separately estimated based on the recent report concerning economic burden of COPD in Korea, which analyzed the database of KHIRA $^{5}$. Severe exacerbations were defined as exacerbations of COPD that lead patients to emergency department visits or to hospitalization.

\section{Patient survey for direct non-medical and indirect cost estimation}

A total of 355 subjects from 13 medical facilities (2 primary, 11 secondary and tertiary facilities) permitted to participate in the present survey and were interviewed with questionnaires between June 2015 and October 2016. The inclusion criteria were same as above mentioned.

Original Questionnaires included demographics, healthrelated quality of life using EQ-5D, informal medical costs, nursing fee, absenteeism, presenteeism, productivity loss, required time for visiting outpatient clinic, caregiver accompanying rate, and history of exacerbation. The amount for CAMS (including non-prescription medicine, health functional food, fork medicine, and Chinese medical service) was aggregated with the expenses on medical and fitness equipment to make informal medical costs. Home care costs were calculated by multiplying home care rate according to the COPD severity, time cost per an hour, and 4 hours of care time a day. Nursing costs were calculated by adding time costs of family caregiver accompanying to home care cost. As for time cost, we adopted the minimum wage 2015 in Korea (4.93 USD and 5,580 KRW per an hour).

Work productivity was assessed using the Work Productivity and Activity Impairment-Specific Health Problem (WPAISHP) questionnaire ${ }^{8}$. The WPAI-SHP measures amounts of absenteeism (work time missed) and presenteeism (impairment at work) as well as daily activity impairment attributable to a specific health problem. The recall period in this questionnaire is 7 days. The costs of loss of productivity were calculated by multiplying the overall productivity lost from the WPAI questionnaire by the average monthly wage.

\section{Statistical analysis}

All statistical analyses were performed using STATA/SE 13 (StataCorp LP, College Station, TX, USA). Pearson's chi-square test was used to compare the distribution of categorical variables. Because the statistics for continuous variables were not normally distributed based on the Shapiro-Wilk test, the nonparametric Kruskal-Wallis test was conducted. A value of $\mathrm{p} \leq 0.05$ was considered statistically significant.

\section{Ethics statement}

The present study protocol was reviewed and approved by the Institutional Review Board of each participating institution. All participants provided written informed consent when they were enrolled.

\section{Results}

\section{Direct medical costs}

\section{1) Direct formal medical costs}

Of the 373 patients participated in the institutional investigation, the mean age was $69.6 \pm 8.7$ years; $74.9 \%$ were in their sixties and seventies; $86.7 \%$ were male; $21.4 \%$ were current smokers. According to the COPD severity, 34 patients (9.1\%) were categorized with mild, 155 (41.6\%) with moderate, 115 (30.8\%) were severe, and 69 (18.5\%) were very severe COPD (Supplementary Table S1). The number of patients who experienced severe exacerbations during the previous year was 55 (14.7\%). The annual number of outpatient department visits was higher in patients with severe exacerbations $(10.8 \pm 5.0)$ than without severe exacerbations (7.5 \pm 4.3$)$. As the COPD severity increased, the annual number of hospitalization and length of hospital stay appeared to be increasing as well as the number of outpatient department visits (Supplementary Table S2).

Direct medical costs related with outpatient and emergency department visits and hospitalization (direct formal medical 
costs except outpatient medication) for a year were 1,000 USD per COPD patient. The costs of patients who experienced severe exacerbations were extremely higher than the other patients. Of course, the costs also tended to increase with increasing the severity of COPD (Supplementary Table S2). The total amount of direct formal medical costs was estimated using the COPD population $(192,496)$ based on the KHIRA database as mentioned above. Overall direct formal medical costs were 206,909 thousand USD (Table 2).

\section{2) Direct informal medical costs}

Of the 355 subjects participated in the survey, $74.4 \%$ were in their sixties and seventies; $91.8 \%$ were males. According to the COPD severity, 43 patients (12.1\%) were categorized with mild, $152(42.8 \%)$ with moderate, $110(31.0 \%)$ were severe, and $50(14.1 \%)$ were very severe COPD (Supplementary Table S1).

A total of $29.3 \%$ of patients spent money on CAMS and medical equipment. The direct informal medical costs was significantly different between the COPD severity groups ( $\mathrm{p}=0.009$ ). Overall direct informal medical costs were 44,239 thousand USD (Table 3 ).

\section{Direct non-medical costs}

The transportation costs per patient appeared to be higher in patients using tertiary medical facilities than in patients using primary and secondary facilities. Overall transportation costs were 4,262 thousand USD (Supplementary Table S3).

Home care costs tended to be higher in very severe COPD patients than in mild to severe COPD patients $(\mathrm{p}=0.056)$. Nursing costs made up the largest percentage of the total estimated costs (39\%) and overall nursing costs were 486.3 million USD (Table 4).

\section{Indirect costs}

Total costs for COPD-related loss of productivity were estimated to be 407,771 thousand USD. The costs appeared to be higher in moderate and severe COPD patients than in mild and very severe patients (Table 5). The costs of COPD-related premature deaths estimated using number of COPD-related deaths and the expected future income were approximately 96,153 thousand USD. The number of premature deaths was greater in male than female COPD patients, and more than $90 \%$ of the total costs were attributed to premature deaths of the male COPD patients (Supplementary Table S4).

Table 2. Direct formal medical costs

\begin{tabular}{|lccccc|}
\hline & \multicolumn{3}{c}{ Medical facility } & \multirow{2}{*}{ p-value } & Total \\
\cline { 2 - 4 } & Primary & Secondary & Tertiary & & 0.470 \\
\hline Total costs per patient* & 375 & 967 & 1,750 & NA & 206,909 \\
\hline Overall costs $^{\dagger}$ & 45,979 & 18,445 & 142,485 & \\
\hline
\end{tabular}

*Marked in US dollar (USD). ${ }^{\dagger}$ In thousand USD.

NA: not applicable.

Table 3. Direct informal medical costs

\begin{tabular}{|c|c|c|c|c|c|c|}
\hline & & COP & rity & & - voln & Totol \\
\hline & Mild & Moderate & Severe & Very severe & p-value & Iotal \\
\hline Use rate, $\%$ & 23.3 & 30.3 & 24.6 & 42.0 & 0.116 & 29.3 \\
\hline $\begin{array}{l}\text { Non-prescription medicine and } \\
\text { Health functional food* }\end{array}$ & 49.5 & 242.3 & 115.8 & 560.0 & 0.853 & 255 \\
\hline Fork medicine* & 148.5 & 389.7 & 443.4 & 988.6 & 0.152 & 501.4 \\
\hline Chinese medical service* & 0.0 & 40.7 & 0.0 & 513.7 & 0.843 & 121.7 \\
\hline Smoking cessation* & 10.6 & 25.1 & 6.5 & 0.0 & 0.966 & 13.8 \\
\hline Exercise* & 39.8 & 19.4 & 0.0 & 0.4 & 0.301 & 12.5 \\
\hline Medical equipment* & 0.0 & 45.4 & 9.7 & 32.9 & 0.768 & 29.2 \\
\hline Total costs per patient* & 248.5 & 762.5 & 575.4 & $2,095.6$ & 0.009 & 933.7 \\
\hline Overall costs $^{\dagger}$ & 622 & 25,302 & 8,676 & 9,639 & NA & 44,239 \\
\hline
\end{tabular}

${ }^{*}$ Marked in US dollar (USD). ${ }^{\dagger}$ In thousand USD.

COPD: chronic obstructive pulmonary disease; NA: not applicable. 


\section{Total estimated costs of COPD}

Total (direct and indirect) costs of COPD in 2015 in Korea are summarized by category in Table 6 . The estimated total costs were 1,245.6 million USD (1,408.8 billion KRW). Direct medical costs comprised approximately $20 \%$ of the total costs. The percentage of nursing costs and lost productivity costs were $39 \%$ and $32.7 \%$ of the total, respectively. These two costs accounted for more than $70 \%$ of the estimated total costs.

\section{Discussion}

The present study was designed to estimate the total costs of COPD in Korea based on the institutional investigation and patient surveys from 13 medical facilities using KHIRA database, Korea Health Panel data, and national statistics. The estimated total costs were approximately 1,245 million USD, which are enormous as much as $0.09 \%$ of gross domestic product of South Korea in 2015. Direct medical costs comprised approximately $20 \%$ of the total estimated costs. Of these, formal medical costs held more than $80 \%$ and tended to increase with increasing the severity of COPD. Informal medical costs, which mean the expense on CAMS and medical equipment, were highest in the group of patients with moder- ate COPD. Nursing costs made up the largest percentage (39\%) of the total estimated costs. As indirect costs, costs for COPDrelated loss of productivity accounted for up to $33 \%$ of the total costs, and were highest in the moderate COPD group.

Because of the increase in the elderly population, chronic diseases are the primary factor that gives rise to medical costs, and the burden of chronic diseases has sharply increased in Korea ${ }^{9}$. Chronic respiratory diseases also have a major adverse impact on quality of life, disability, and productivity, resulting in an increased socioeconomic burden ${ }^{10}$. In the present study, the mean annual cost per a Korean COPD patient was about 6.5 thousand USD. This result corresponds with a most recent report that has evaluated burden of respiratory diseases in Korea, which showed that the annual cost per patient of COPD was more than 7.0 thousand USD ${ }^{10}$.

In addition, the accurate burden of a disease on individuals, family, and society is not reflected only by direct costs but also by indirect costs, which may account for a substantial proportion. The present study revealed that more than $40 \%$ of the total annual costs of COPD were indirect. Of the indirect costs, around $80 \%$ was for the costs of loss of productivity. In a review of literature concerning the indirect burden of COPD in the United States, indirect costs (mostly absence and disability costs) accounted for $30 \%-60 \%$ of total costs, with the higher estimates produced by the studies of working age pop-

Table 4. The expense for nursing

\begin{tabular}{|c|c|c|c|c|c|c|}
\hline & \multicolumn{4}{|c|}{ COPD severity } & \multirow{2}{*}{ p-value } & \multirow{2}{*}{ Tota } \\
\hline & Mild & Moderate & Severe & Very severe & & \\
\hline Caregiver accompanying costs per patient* & 16.1 & 44.3 & 75.0 & 127.5 & NA & \\
\hline Home care costs per patient* & $2,057.9$ & $2,480.8$ & $2,292.1$ & $3,745.7$ & 0.056 & \\
\hline Nursing costs per patient* & $2,074.0$ & $2,525.0$ & 2,367.1 & $3,873.2$ & NA & \\
\hline Overall costs ${ }^{\dagger}$ & 22.3 & 276.5 & 145.1 & 42.4 & NA & 486.3 \\
\hline
\end{tabular}

*Marked in US dollar (USD). 'In million USD.

COPD: chronic obstructive pulmonary disease; NA: not applicable.

Table 5. The costs of COPD-related loss of productivity

\begin{tabular}{|c|c|c|c|c|c|c|}
\hline & \multicolumn{4}{|c|}{ COPD severity } & \multirow{2}{*}{ p-value } & \multirow{2}{*}{ Total } \\
\hline & Mild & Moderate & Severe & Very severe & & \\
\hline Economic activity, \% & 32.56 & 25.83 & 22.02 & 16.33 & 0.285 & 24.15 \\
\hline Work time missed & 14 & 26 & 100 & 825 & 0.008 & 127 \\
\hline Work time missed, \% & 0.01 & 0.01 & 0.06 & 0.22 & 0.001 & 0.04 \\
\hline Impairment at work, \% & 0.07 & 0.21 & 0.28 & 0.50 & 0.003 & 0.24 \\
\hline WPAI score & 0.08 & 0.22 & 0.32 & 0.61 & 0.004 & 0.27 \\
\hline Costs of loss of productivity per patient* & 0.85 & 1.95 & 2.42 & 3.43 & NA & 2.21 \\
\hline Total costs of loss of productivity* & 9,115 & 213,340 & 148,066 & 37,250 & NA & 407,771 \\
\hline
\end{tabular}

*Marked in thousand US dollar.

COPD: chronic obstructive pulmonary disease; WAPI: work productivity and activity impairment; NA: not applicable. 
Table 6. Total estimated costs of COPD in Korea

\begin{tabular}{|lcc|}
\hline \multicolumn{1}{|c}{ Category } & Costs (million USD) & Percentage \\
\hline Direct medical & & \\
\hline Formal & 206.9 & 16.6 \\
\hline Informal & 44.2 & 3.5 \\
\hline Direct non-medical & & \\
$\quad$ Transportation & 4.3 & 0.3 \\
Nursing & 486.3 & 39.0 \\
\hline Indirect & & 32.7 \\
Loss of productivity & 407.8 & 7.7 \\
\hline Premature deaths & 96.2 & 100 \\
\hline Total & $1,245.6$ & \\
\hline
\end{tabular}

COPD: chronic obstructive pulmonary disease; USD: US dollar.

ulations $^{11}$. A recent study investigated the burden of chronic prevalent respiratory diseases in Korea also demonstrate that lost productivity was the main contributor to overall $\operatorname{costs}^{10}$. So the indirect cost estimation of the present study was roughly correlated with these results.

In some studies, direct non-medical costs (not attributable to inpatient or outpatient care or medication) contributed to a significant fraction of total direct costs ${ }^{1,12}$. In the present study, nursing costs are responsible for a considerable proportion of overall COPD burden as well. As would be expected, home care costs per patient were overwhelmingly high in the group of patients with very severe COPD. Moreover, caregiver accompanying costs were also highest in very severe COPD patients. However, this proportion of costs for nursing was relatively greater than those of previous total COPD burden studies of western countries ${ }^{13,14}$. It may be mainly attributable to the Korean's traditional sentiments of taking care of their parents, as well as old age and decreased physical activity which are the characteristics of COPD population.

In addition, nearly $30 \%$ of COPD patients spent their money on CAMS and medical and fitness equipment. These informal medical costs comprised $17.6 \%$ of the direct medical costs. Most of them were used for fork medicine, health functional food, and Chinese medical service. Costs used for medical equipment and exercise were very small and accounted for based treatment for symptomatic patients with COPD, and exercise training is regarded as the cornerstone of rehabilitation program $^{15}$. It is recommended that all patients who experience shortness of breath when walking on their own pace on level ground should be offered rehabilitation ${ }^{16}$. However, pulmonary rehabilitation remains largely underutilized in the real world of Korea in spite of documented efficacy and strong recommendations. We think it may be more cost effective for patients with COPD to spend money on fitness equipment and exercise rather than on CAMS.
The present study had several limitations. First, this result was not the true economic burden of a total COPD population in Korea but an estimated burden using a relatively small group of COPD patients. However, we recruited patients from various medical facilities including primary, secondary, and tertiary care hospitals, and the estimation was based on the real world COPD population according to the KHIRA database. Second, we used the data from patient survey to estimate direct informal, direct non-medical, and indirect costs of COPD for the first time in Korea. Although it was done thoroughly, the survey data were entirely patient-reported, and therefore subject to recall bias. So we cannot exclude the possibility of overestimation of the costs of lost productivity and nursing, which comprised $71.7 \%$ of total costs, due to inaccurate or fabricated memories. Third, we tried to recruit patients from primary clinics to tertiary hospitals, but a large number of patients were enrolled from the referral centers. Actually, COPD patients attending tertiary and general hospitals constituted about $70 \%$ of the total COPD population in the evaluation of appropriate management of COPD in Korea based on KHIRA claim data ${ }^{17}$. In the present study, direct formal medical costs per patient were much higher in tertiary care hospitals than in primary and secondary care facilities. It is also likely that patients from the referral hospitals have more severe diseases and higher costs. Hence, the overall costs may be overestimated.

In conclusion, the present study represented for the first time the direct and indirect economic burden of COPD in Korea. The total estimated costs were approximately 1,245 million USD (1,408 billion KRW), and the costs of nursing and lost productivity comprised approximately $70 \%$ of total costs. These results suggest new insight into efficient healthcare provision and fundamental data to establish practical strategies to reduce burden of COPD in Korea. Further prospective studies in larger patient samples from more various medical facilities are warranted to clarify the results of the present study and to estimate total economic burden more precisely.

\section{Authors' Contributions}

Conceptualization: Yoo KH. Methodology: Yoo KH, Rhee CK, Kim Y, Yang DW. Formal analysis: Kim Y, Yang DW. Data curation: Yoo KH, Kim C, Kim Y, Yang DW. Enrollment of the patients: Rhee CK, Kim SK, Hwang YI, Park YB, Lee YM, Jin S, Park J. Hahm CR, Park CH, Park SY, Jung CK, Kim YI, Lee SH, Yoon HK, Lee JH, Lim SY, Yoo KH. Writing - original draft preparation: Kim C, Kim Y, Yoo KH. Writing - review and editing: Kim C, Park YB, Yoo KH. Approval of final manuscript: all authors. 


\section{*Author affiliations}

${ }^{1}$ Department of Internal Medicine, Jeju National University Hospital, Jeju National University School of Medicine, Jeju, ${ }^{2}$ Institute of Health and Environment, School of Public Health, Seoul National University, Seoul, ${ }^{3}$ Graduate School of Public Health, Seoul National University, Seoul, ${ }^{4}$ Department of Internal Medicine, Seoul St. Mary's Hospital, College of Medicine, The Catholic University of Korea, Seoul, ${ }^{5}$ Department of Internal Medicine, St. Vincent's Hospital, College of Medicine, The Catholic University of Korea, Suwon, ${ }^{6}$ Department of Internal Medicine, Hallym University Sacred Heart Hospital, Anyang, ${ }^{7}$ Department of Internal Medicine, Hallym University Kangdong Sacred Heart Hospital, Seoul, ${ }^{8} \mathrm{GF}$ Allergy Clinic, Seoul, ${ }^{9}$ Beautiful Breath Clinic, Seoul, Korea, ${ }^{10}$ Channing Division of Network Medicine, Department of Medicine, Brigham and Women's Hospital, Boston, MA, USA, ${ }^{11}$ Department of Internal Medicine, Gwangmyeong Sungae Hospital, Seoul, ${ }^{12}$ Department of Internal Medicine, Sungae Hospital, Seoul, ${ }^{13}$ A\&A Clinic, Seoul, ${ }^{14}$ Sanbon Yonsei Clinic, Gunpo, ${ }^{15}$ Department of Internal Medicine, Chonnam National University Hospital, Gwangju, ${ }^{16}$ Department of Internal Medicine, St. Paul's Hospital, College of Medicine, The Catholic University of Korea, Seoul, ${ }^{17}$ Department of Internal Medicine, Yeouido St. Mary's Hospital, College of Medicine, The Catholic University of Korea, Seoul, ${ }^{18}$ Department of Internal Medicine, School of Medicine, Ewha Womans University, Seoul, ${ }^{19}$ Department of Medicine, Kangbuk Samsung Hospital, Sungkyunkwan University School of Medicine, Seoul, ${ }^{20}$ Department of Internal Medicine, Konkuk University School of Medicine, Seoul, Korea

\section{Conflicts of Interest}

This study was supported by a grant of GlaxoSmithKline.

\section{Acknowledgments}

We authors sincerely thank the following institutions and individuals for their participation and great help: Konkuk University Hospital, Yeouido St. Mary's Hospital, Kangbuk Samsung Hospital, Seoul St. Mary's Hospital, Ewha Womans University Mokdong Hospital, Chonnam National University Hospital, St. Vincent's Hospital, Hallym University Kangdong Sacred Heart Hospital, Gwangmyeong Sungae Hospital, St. Paul's Hospital, Sungae Hospital, GF Allergy Clinic, Beautiful Breath Clinic, A\&A Clinic, Sanbon Yonsei Clinic.

\section{Supplementary Material}

Supplementary material can be found in the journal homepage (http://www.e-trd.org).

Supplementary Table S1. Demographic data of the participants.

Supplementary Table S2. Patients' characteristics and direct formal medical costs per COPD patient.

Supplementary Table S3. The expense for transportation.

Supplementary Table S4. The costs of premature deaths caused by COPD.

\section{References}

1. Ehteshami-Afshar S, FitzGerald JM, Doyle-Waters MM, Sadatsafavi M. The global economic burden of asthma and chronic obstructive pulmonary disease. Int J Tuberc Lung Dis 2016;20:11-23.

2. Terzikhan N, Verhamme KM, Hofman A, Stricker BH, Brusselle GG, Lahousse L. Prevalence and incidence of COPD in smokers and non-smokers: the Rotterdam Study. Eur J Epidemiol 2016;31:785-92.

3. Hwang YI, Park YB, Yoo KH. Recent trends in the prevalence of chronic obstructive pulmonary disease in Korea. Tuberc Respir Dis 2017;80:226-9.

4. Yoo KH, Kim YS, Sheen SS, Park JH, Hwang YI, Kim SH, et al. Prevalence of chronic obstructive pulmonary disease in Korea: the fourth Korean National Health and Nutrition Examination Survey, 2008. Respirology 2011;16:659-65.

5. Kim C, Yoo KH, Rhee CK, Yoon HK, Kim YS, Lee SW, et al. Health care use and economic burden of patients with diagnosed chronic obstructive pulmonary disease in Korea. Int J Tuberc Lung Dis 2014;18:737-43.

6. Rhee CK, Yoon HK, Yoo KH, Kim YS, Lee SW, Park YB, et al. Medical utilization and cost in patients with overlap syndrome of chronic obstructive pulmonary disease and asthma. COPD 2014;11:163-70.

7. Lee JY, Chon GR, Rhee CK, Kim DK, Yoon HK, Lee JH, et al. Characteristics of patients with chronic obstructive pulmonary disease at the first visit to a pulmonary medical center in Korea: the KOrea COpd Subgroup Study Team Cohort. J Korean Med Sci 2016;31:553-60.

8. Reilly MC, Zbrozek AS, Dukes EM. The validity and reproducibility of a work productivity and activity impairment instrument. Pharmacoeconomics 1993;4:353-65.

9. Kim EJ, Yoon SJ, Jo MW, Kim HJ. Measuring the burden of chronic diseases in Korea in 2007. Public Health 2013;127:806-13.

10. Yoo KH, Ahn HR, Park JK, Kim JW, Nam GH, Hong SK, et al. Burden of respiratory disease in Korea: an observational study on allergic rhinitis, asthma, COPD, and rhinosinusitis. Allergy Asthma Immunol Res 2016;8:527-34.

11. Patel JG, Nagar SP, Dalal AA. Indirect costs in chronic obstructive pulmonary disease: a review of the economic burden on employers and individuals in the United States. Int J Chron 
Obstruct Pulmon Dis 2014;9:289-300.

12. Akazawa M, Halpern R, Riedel AA, Stanford RH, Dalal A, Blanchette CM. Economic burden prior to COPD diagnosis: a matched case-control study in the United States. Respir Med 2008;102:1744-52.

13. Dal Negro RW, Tognella S, Tosatto R, Dionisi M, Turco P, Donner CF. Costs of chronic obstructive pulmonary disease (COPD) in Italy: the SIRIO study (social impact of respiratory integrated outcomes). Respir Med 2008;102:92-101.

14. Gershon AS, Guan J, Victor JC, Goldstein R, To T. Quantifying health services use for chronic obstructive pulmonary disease. Am J Respir Crit Care Med 2013;187:596-601.
15. Troosters T, Gosselink R, Janssens W, Decramer M. Exercise training and pulmonary rehabilitation: new insights and remaining challenges. Eur Respir Rev 2010;19:24-9.

16. Yoon HK, Park YB, Rhee CK, Lee JH, Oh YM; Committee of the Korean COPD Guideline 2014. Summary of the chronic obstructive pulmonary disease clinical practice guideline revised in 2014 by the Korean Academy of Tuberculosis and Respiratory Disease. Tuberc Respir Dis 2017;80:230-40.

17. Chung SM, Lee SY. Evaluation of appropriate management of chronic obstructive pulmonary disease in Korea: based on Health Insurance Review and Assessment Service (HIRA) claims. Tuberc Respir Dis 2017;80:241-6. 
Supplementary Table S1. Demographic data of the participants

\begin{tabular}{|c|c|c|c|c|c|}
\hline & \multicolumn{4}{|c|}{ COPD severity } & \multirow{2}{*}{$\begin{array}{c}\text { Total } \\
(n=373)\end{array}$} \\
\hline & $\begin{array}{c}\text { Mild } \\
(n=34)\end{array}$ & $\begin{array}{c}\text { Moderate } \\
(n=155)\end{array}$ & $\begin{array}{c}\text { Severe } \\
(n=115)\end{array}$ & $\begin{array}{l}\text { Very severe } \\
\quad(n=69)\end{array}$ & \\
\hline Male sex & $23(67.6)$ & $123(79.4)$ & $98(85.2)$ & $55(79.7)$ & $299(80.2)$ \\
\hline $50-59$ & 3 & 16 & 10 & 13 & 42 \\
\hline $60-69$ & 6 & 47 & 34 & 26 & 113 \\
\hline $70-79$ & 15 & 63 & 48 & 18 & 144 \\
\hline $80-89$ & 5 & 14 & 14 & 7 & 40 \\
\hline Male sex & 41 (95.3) & 138 (90.8) & $102(92.7)$ & $45(90.0)$ & 326 (91.8) \\
\hline \multicolumn{6}{|l|}{ Age, yr } \\
\hline $40-49$ & 2 & 3 & 1 & 2 & 8 \\
\hline $50-59$ & 4 & 14 & 11 & 9 & 38 \\
\hline $60-69$ & 13 & 44 & 28 & 18 & 103 \\
\hline $70-79$ & 20 & 67 & 55 & 19 & 161 \\
\hline 80-89 & 4 & 24 & 15 & 2 & 45 \\
\hline
\end{tabular}

Values are presented as number (\%).

COPD: chronic obstructive pulmonary disease. 
Supplementary Table S2. Patients' characteristics and direct formal medical costs per COPD patient

\begin{tabular}{|c|c|c|c|c|c|c|}
\hline & \multicolumn{4}{|c|}{ COPD severity } & \multirow{2}{*}{ p-value } & \multirow{2}{*}{ Total } \\
\hline & Mild & Moderate & Severe & Very severe & & \\
\hline Patient & $34(9.1)$ & $155(41.6)$ & $115(30.8)$ & $69(18.5)$ & NA & $373(100)$ \\
\hline Patients with severe $\mathrm{AE}$ & $4(11.8)$ & $13(8.4)$ & $17(14.8)$ & $21(30.4)$ & $<0.001$ & $55(14.7)$ \\
\hline \multicolumn{7}{|l|}{ OPD visits } \\
\hline Previous severe AE (-) & $6.0 \pm 3.6$ & $7.2 \pm 4.4$ & $7.9 \pm 4.2$ & $8.1 \pm 4.4$ & 0.019 & $7.5 \pm 4.3$ \\
\hline Previous severe AE (+) & $8.8 \pm 3.6$ & $9.8 \pm 5.1$ & $10.8 \pm 5.8$ & $11.8 \pm 4.6$ & 0.382 & $10.8 \pm 5.0$ \\
\hline Total & $6.3 \pm 3.7$ & $7.5 \pm 4.5$ & $8.3 \pm 4.5$ & $9.2 \pm 4.7$ & 0.001 & $7.9 \pm 4.5$ \\
\hline \multicolumn{7}{|l|}{ No. of hospitalization } \\
\hline Previous admission (+) & $1.0 \pm 0.0$ & $1.5 \pm 1.0$ & $1.6 \pm 0.9$ & $1.7 \pm 0.9$ & 0.231 & $1.6 \pm 0.9$ \\
\hline Total & $0.1 \pm 0.3$ & $0.1 \pm 0.5$ & $0.2 \pm 0.7$ & $0.5 \pm 0.9$ & 0.052 & $0.2 \pm 1.6$ \\
\hline \multicolumn{7}{|l|}{ Hospital stay, day } \\
\hline Previous admission $(+)$ & $6.0 \pm 2.6$ & $8.9 \pm 4.6$ & $15.6 \pm 16.0$ & $13.6 \pm 8.0$ & 0.077 & $12.7 \pm 10.7$ \\
\hline Total & $0.5 \pm 1.8$ & $0.7 \pm 2.8$ & $2.8 \pm 8.2$ & $4.1 \pm 7.7$ & 0.048 & $1.8 \pm 6.0$ \\
\hline \multicolumn{7}{|l|}{ Medical costs per patient* } \\
\hline Severe AE $(-)$ & $240 \pm 211$ & $240 \pm 168$ & $274 \pm 209$ & $376 \pm 540$ & 0.202 & $271 \pm 275$ \\
\hline Severe AE (+) & $1,196 \pm 492$ & $4,122 \pm 3,045$ & $6,536 \pm 7,418$ & $5,581 \pm 3,598$ & 0.021 & $5,212 \pm 5,025$ \\
\hline Total costs per patient* & $352 \pm 399$ & $566 \pm 1,383$ & $1,200 \pm 3,570$ & $1,960 \pm 3,135$ & $<0.001$ & $1,000 \pm 2,609$ \\
\hline
\end{tabular}

Values are presented as number (\%) or mean \pm standard deviation.

*Marked in US dollar.

COPD: chronic obstructive pulmonary disease; NA: not applicable; AE: acute exacerbation; OPD: outpatient department. 
Supplementary Table S3. The expense for transportation

\begin{tabular}{|c|c|c|c|c|c|}
\hline & Primary & Secondary & Tertiary & p-value & Total \\
\hline \multicolumn{6}{|c|}{ Transportation fee per case (one way)* } \\
\hline OPD & 0.46 & 1.14 & 2.66 & 0.000 & \\
\hline Admission & 1.67 & 5.47 & 8.36 & 0.001 & \\
\hline \multicolumn{6}{|l|}{ No. of visits } \\
\hline OPD & 12.8 & 9.3 & 6.3 & 0.000 & \\
\hline Admission & & 0.2 & 0.2 & 0.724 & \\
\hline Costs per patient* & 11.7 & 24.0 & 37.5 & NA & \\
\hline Overall costs ${ }^{\dagger}$ & 1,235 & 395 & 2,632 & NA & 4,262 \\
\hline
\end{tabular}

*Marked in US dollar (USD), ${ }^{\dagger}$ In thousand USD.

OPD: outpatient department; NA: not applicable. 
Supplementary Table S4. The costs of premature deaths caused by COPD

\begin{tabular}{|c|c|c|c|c|c|c|}
\hline \multirow{2}{*}{ Age (yr) } & \multicolumn{2}{|c|}{ COPD-related deaths } & \multicolumn{2}{|c|}{ Expected future income* } & \multicolumn{2}{|c|}{ Costs of premature deaths* } \\
\hline & Male & Female & Male & Female & Male & Female \\
\hline $40-44$ & 6 & 3 & 509 & 184 & 3,054 & 552 \\
\hline $45-49$ & 12 & 6 & 423 & 150 & 5,079 & 900 \\
\hline $50-54$ & 38 & 8 & 316 & 111 & 12,017 & 884 \\
\hline $55-59$ & 77 & 25 & 204 & 71 & 15,725 & 1,782 \\
\hline $60-64$ & 135 & 35 & 111 & 38 & 14,962 & 1,341 \\
\hline $65-69$ & 274 & 77 & 51 & 17 & 14,091 & 1,298 \\
\hline $70-74$ & 512 & 114 & 25 & 8 & 13,030 & 917 \\
\hline $75-79$ & 945 & 246 & 10 & 3 & 9,716 & 805 \\
\hline Subtotal & 2,004 & 519 & & & 87,675 & 8,478 \\
\hline Total & & & & & & 96,153 \\
\hline
\end{tabular}

*Marked in thousand US dollar.

COPD: chronic obstructive pulmonary disease. 